\title{
Effect of Aloe Vera Extract on Reducing Aflatoxin B1 in Eggs of Laying Hen and Egg Yolk Oxidative Stability
}

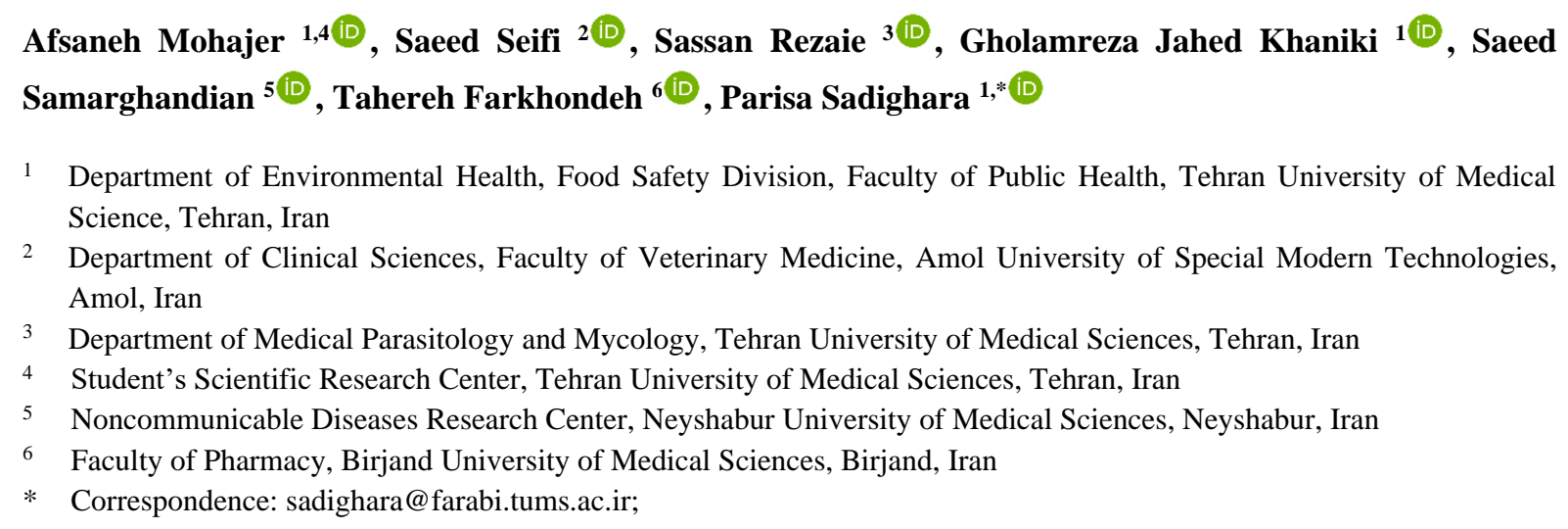

Received: 19.12.2020; Revised: 20.01.2021; Accepted: 24.01.2021; Published: 31.01.2021

Abstract: Aloe vera extract's effect on Aflatoxin B1 (AFB1) residue and yolk oxidative stability was examined in yolk samples. The results indicated that residue of AB1 in AF-Aloe (100 and 300 ppm) treated groups were lower than the control groups on day 14 and was not detected on day 28. The lipid peroxidation level in all groups was significantly $(\mathrm{p}<0.05)$ lower than the positive control group. The weight, production, and carotenoid of eggs were not statistically significant between the groups. These results indicate that Aloe vera extract can be effective in diminishing AFB1.

Keywords: aflatoxin B1; Aloe vera; yolk; oxidative stability; egg.

(C) 2021 by the authors. This article is an open-access article distributed under the terms and conditions of the Creative Commons Attribution (CC BY) license (https://creativecommons.org/licenses/by/4.0/).

\section{Introduction}

Fungal toxins are known as mycotoxins. Although there are various produced mycotoxins from different fungi, some of them are more popular and toxic. They can enter the food chain and lead to contamination. Therefore, fungal toxins have detrimental effects on animals and human health [1]. Some main mycotoxins, such as Aflatoxins, Ochratoxins, Zearalenone, T-2 toxin, deoxynivalenol, and fumonisins, have been detected in the feeds [2]. Aflatoxins (AFs) are a secondary toxic fungal metabolite that is produced from Aspergillus flavus and Aspergillus parasiticus [3]. These fungi can grow under any stage of growing, harvesting, pre-harvesting, storage, and transportation conditions. AFs are typically found in dried fruits, dairy products, meat, and eggs [4]. They damage the crops every year and, for this reason, AFs are considered a worldwide problem [5]. AFs are classified into four groups, including AFB1, AFB2, AFG1, and AFG2 [6]. Aflatoxin B1 is a dangerous toxin among the mycotoxins and set in Group 1 carcinogens by the International Agency for Research on Cancer (IARC, 1993) [7]. Generally, AFB1 contaminates feeds, which leads to contaminated animals and also animal products. Thus, ingestion of contaminated food results in human infection [8]. One of the main factors of AFB1 intoxications is the level of ingestion dose and exposure time. Numerous studies have shown acute and chronic aflatoxicosis (the poisoning that results from 
ingesting aflatoxins) in humans and animals [9]. Aflatoxicosis problems are considered in the poultry industry. It can lead to anorexia and low food intake, weight loss, disruption of egg production, and enhanced chicks' mortality. The accumulation of AF in a chicken's soft and fat tissues can lead to fatty muscle syndrome. Therefore, controlling aflatoxins in the chickens' feeds is very important to protect public health, bird health and maintain the poultry industry [10]. Some procedures prevent or reduce AFB1, such as the chemical, physical, and biological methods. However, previous studies have shown that these methods are not always efficient and economical [11]. Since ancient times, plant extracts used to cure and prevent diseases. This method is still useful as an effective, safe, and harmless rather than chemical strategy after many years. Medicinal herbs are a source of antimicrobial agents, which are part of the secondary metabolites of plants. Several studies have reported that extracts and powders of plants have antifungal activity, and some of them can prevent Aflatoxin production [12,13]. One of the most important medicinal plants is Aloe vera. Aloe vera (Aloe barbadensis Miller) is a perennial herb belonging to the family Liliaceae. This plant contains a variety of compounds, including phenol, saponins, and anthraquinones. These compounds have antibacterial, virus, and fungal activity [14]. Aloe vera is widely used and sold due to its nutritional and therapeutic properties. It is also easily useable and economical. Previous studies have approved Aloe vera detoxification activity [15]. According to the mentioned points, this research work was performed to determine the Aloe vera extract effect on reducing Aflatoxin B1 in laying hen eggs and yolk oxidative stability.

\section{Materials and Methods}

\subsection{Chemicals and reagents.}

In the current study, Aflatoxin B1 was purchased from Farogh Company, Iran. Aloe vera powder was obtained from Barij essence company, Iran. The ELISA kit was obtained from R-biopharma Company, Germany, and other chemicals from Sigma Aldrich.

\subsection{Experimental design, diets, and collection of samples.}

Twenty- eight of 25-week-old layers hens (White Leghorn) were used and fed ad libitum for 14 and 28 days. According to the LD 50 dose $(6.3 \mathrm{mg} / \mathrm{kg})$ for chickens, a quarter of it (1575 $\mu$ g of AFB1/kg b.w) was calculated and used for the current work (Jones, 2011) [16]. The hens were kept at room temperature $\left(22^{\circ} \mathrm{C}\right)$ and relative humidity $(75 \%)$. Lighting consisted of 16L: 8D. The hens were divided into four groups, each group involving seven birds. Group 1 as a negative control group just fed with standard layer diet (0-0), group 2 given with contaminated feed (AF-0) as a positive control group (AF-0), group 3 fed with the contaminated feed associate with $100 \mathrm{ppm}$ dose of Aloe vera powder (AF-Aloe100), and group 4 fed with contaminated feed with $300 \mathrm{ppm}$ dose of Aloe vera powder (AF-Aloe300). After the end of the experiment (28 days), the 50 egg samples were collected and kept in the refrigerator until analyzed.

\subsection{Assay of aflatoxin B1 residues in eggs on days 14 and 28.}

The amount of AFB1 residue in egg yolk samples was examined based on the AB1 ELISA Kit protocol on days 14 and 28. Briefly, $5 \mathrm{~g}$ of the ground and homogenized sample was weighted and added $25 \mathrm{ml}$ of $70 \%$ methanol. It was shaken for three minutes (manually 
or with a shaker) and filtered. Then, $1 \mathrm{ml}$ of the obtained filtrate was diluted with $1 \mathrm{ml}$ of distilled water. In the end, $50 \mu \mathrm{l}$ of the diluted filtrate was added per well in the test. The detection limit and recovery rates were $1.72 \mu \mathrm{g} / \mathrm{kg}$ and $93 \%$, respectively.

\subsection{Assay of lipid peroxidation as a yolk oxidative stability indicator.}

Malondialdehyde (MDA) levels, as an index of lipid peroxidation, were evaluated in this study. MDA reacts with thiobarbituric acid (TBA) as a thiobarbituric acid reactive substance (TBARS) to produce a red-colored complex, which can be determined spectrophotometrically. According to the previous method [17,18], in the current study, the amounts of lipid peroxidation in yolk egg samples were detected by measuring the formation of thiobarbituric acid reactive substances. The samples were mixed with $20 \%$ TCA (Trichloroacetic acid) and centrifuged at $20000 \mathrm{rpm}$ for $20 \mathrm{~min}$. Then, TBA was added to the supernatant and heated. The absorbance was read at $532 \mathrm{~nm}$. The values were expressed in nmol MDA, using a molar extinction coefficient of $1.56 \times 105 \mathrm{M}^{-1} \mathrm{~cm}^{-1}$.

\subsection{Assay of egg production and egg weight.}

In the current study, the egg production was calculated and compared with the negative control group on the day of the 7th, 14th, 21th, and 28th each week. Besides, the eggs' weight was measured using a digital weighing scale (0.001g accuracy).

\subsection{Assay of carotenoid in egg yolk.}

Egg samples were cleaned with distilled water and dried at room temperature. After the eggs were broken, the white part separated from the yolk. Then each yolk was extracted and analyzed in triplicates according to the AOAC method (AOAC,1973) [19], one gram of wellmixed egg yolk from each egg was taken afterward, acetone was added to the egg yolk in two steps, first $1 \mathrm{ml}$ to make a smooth paste and after that $50 \mathrm{ml}$. The solution was mixed and filtered (equivalent to Whatman Nr. 4). After washing the filter with acetone, the recovered acetone diluted up to $100 \mathrm{ml}$. Yolk pigmentation is equivalent to $\mu \mathrm{g} ß$-carotene/g sample that measured on a spectrophotometer at $450 \mathrm{~nm}$ wavelength.

\subsection{Statistical analysis.}

All assessments were performed in duplicate. Statistical analyses were conducted using Statistical Package for the Social Sciences (SPSS Inc., USA) version 16.0. One-way analysis of variance (ANOVA) and Dunnett's post hoc test was done to compare all the groups versus the control group. The Kolmogorov-Simonov test was used to assess the normal distribution of quantitative variables. Those exhibiting a normal distribution were represented by a mean and standard deviation. Differences of $\mathrm{p}<0.05$ were considered statically significant. Figures were drawn using Graph Pad Prism 7. 


\section{Results and Discussion}

\subsection{Results.}

\subsubsection{Aflatoxin B1 residue on days 14 and 28.}

To evaluate Aloe vera extract's effects in hens fed an AFB1-contaminated diet, animals within different treatment groups either received AFB1 alone or in a mixture with the Aloe vera extract for 28 days. The comparison of the findings is shown in Figure 1. The results indicated that the highest level of AFB1 was observed in positive control groups $(0.07 \pm 0.007 \mu \mathrm{g} / \mathrm{kg}$ for day $14,0.08 \pm 0.008 \mu \mathrm{g} / \mathrm{kg}$ for day 28), and the lowest level of AFB1 was detected in the group treated with AF-Aloe100 $(0.03 \pm 0.003 \mu \mathrm{g} / \mathrm{kg})$ compared with the positive control groups on day14. There were significant differences between the dose of 100 and $300 \mathrm{ppm}$ on day14 $(\mathrm{p}<0.05)$. No residues of AFB1 were observed in egg yolk treated groups with AF-Aloe 300 on day 28.

\subsubsection{Lipid peroxidation in egg yolk.}

In the current study, yolk oxidative stability was measured. Results showed that the level of lipid oxidation was significantly different amongst groups ( $\mathrm{p}-\mathrm{Value}=0.02)$. The highest level of lipid peroxidation was found in positive control groups $(1.19 \pm 0.2$ for day $14,1.30 \pm$ $0.3 \mathrm{nmol} / \mathrm{g}$ for day 28). The lowest amounts of lipid peroxidation were detected in group AFAloe with a dose of $300 \mathrm{ppm}$ on day $28(0.7 \pm 0.08 \mathrm{nmol} / \mathrm{g})$. The response of lipid peroxidation in yolk egg is presented in Figure 2.

\subsubsection{Egg production and egg weight.}

Due to the egg weight and egg production results, no significant difference between control and treated groups was found $(\mathrm{p}>0.05)$, (Table 1$)$.

\subsubsection{Carotenoid in egg yolk.}

The results were found that the level of carotenoid in egg yolk samples was the same in all groups, and no significant difference was found ( $p>0.05)$. The results are shown in Figure 3.

\subsection{Discussion.}

\subsubsection{AflatoxinB1 residue in the egg.}

AB1-contaminated feed results in contamination of animal products such as meat, eggs, milk. Previous studies and the current study have proved it. Therefore, AFB1 can enter the human body through the ingestion of contaminated foods [20]. The toxic traits of AFB1 are due to the bioavailability of AFB1-8.9 epoxy to cellular macromolecules, especially nucleic acids, nucleoproteins, and mitochondria, which lead to cytotoxic effects during the short and long time [21]. Various reports have been documented the harmful effects and control strategies of AFB1 on Poultry [22]. Although limited reports have been recorded for the presence of mycotoxins contamination in chicken meat and eggs, it has risen today [23]. Previous studies have shown the natural incidence of Aflatoxins in chicken meat and eggs. The results indicated that from 115 chicken meat and 80 egg samples, 35\% of chicken samples and 
$28 \%$ of samples of eggs were found contaminated with AFs [24]. Food and Drug Administration (FDA) has settled guidelines for the maximum total AF level permitted in poultry feed, which is $20 \mathrm{ppb}$ in corn and peanut products for chicks and $100 \mathrm{ppb}$ in feed for adult chickens (FDA, 2009) [25]. This current experimental model was conducted in four weeks. The results determined that the amount of AFB1 residues in egg yolk samples of the hens treated with AFB1 plus Aloe vera powder were significantly reduced or non-detectable compared to the hens just fed with Aflatoxin B1. Based on the obtained data, dose-response was observed by the increase of Aloe vera dose from 100 to $300 \mathrm{ppm}$ on days 14 and 28. In other words, with the increasing dose of Aloe vera, the toxicity level decreased. Also, the time factor was effective. As Figure 1 shows, no residues of Aflatoxin B1 were detected on day 28 with an Aloe vera dose of $300 \mathrm{ppm}$. Also, a significant difference was observed with increasing doses from $100(0.03 \pm 0.003 \mu \mathrm{g} / \mathrm{g})$ to $300(0 \pm 0 \mu \mathrm{g} / \mathrm{g}) \mathrm{ppm}$ on day 14 . This can be due to the effect of a longer period compared with the $14^{\text {th }}$ day of treatment, which has a greater chance of reducing toxicity. Although there is no study on Aloe vera effect in residues AFB1 in chickens egg, a similar study has been carried out regarding Aloe vera effects on AFB1 in another animal model, which showed that Aloe vera powder has been very effective in reducing the toxicity of Aflatoxin B1 [15]. Different new strategies have been done to decrease the toxicity of Aflatoxin B1 in chickens, such as using lactic acid bacteria [26] in the drinking water of broiler chickens that led to reductions in AFB1 of $55.46 \%$ (1.19 to $0.43 \mathrm{ng} / \mathrm{g}$ ), $37.68 \%$ $(0.69$ to $0.53 \mathrm{ng} / \mathrm{g})$ in leg and breast, respectively, at the end of week 6 . The concentration of AFB1 in liver, kidney, and gizzard was reduced by $60.68 \%$ (1.88 to $0.74 \mathrm{ng} / \mathrm{g}), 60.64 \%$ (2.06 to $0.81 \mathrm{ng} / \mathrm{g}$ ), and $52.73 \%(1.10$ to $0.52 \mathrm{ng} / \mathrm{g})$, respectively. In another study, the effects of zeolite in residues of AFB1 in laying duck were revealed. Zeolite inclusion did not significantly ( $\mathrm{P}>0.05)$ reduce AFB1 and AFM1 concentrations in meat, liver, and eggs [27]. Previous studies for controlling Aspergillus flavus and Aspergillus parasiticus growth and Aflatoxin production were done in poultry feed using carvacrol and trans-cinnamaldehyde, which had a positive result in reducing Aspergillus flavus and Aspergillus parasiticus growth and AFB1 production [6]. Although the addition of AF-binding adsorbent in the feed is applied to protect poultry from the harmful effects of AF, it has led to impaired nutrient consumption [28] and mineral intake in chickens [29]. Therefore, the approaches to control AF are not adequate, which means that effective and necessary food safety strategies are needed [30].

\subsubsection{Lipid peroxidation in yolk egg.}

One-third of the egg yolk consists of lipids. Lipids are one of the food components that are likely to be oxidized easily. The oxidation process changes several interactions among food ingredients, leading to unfavorable products $[17,18]$. The present findings indicated that Aloe vera powder decreases lipid peroxidation in yolk eggs. The highest and lowest lipid peroxidation level was detected in AF-0 group $(1.30 \mathrm{nmol} / \mathrm{gr})$ and AF-Aloe group (0.79 $\mathrm{nmol} / \mathrm{g}$ ) with the dose of $300 \mathrm{ppm}$, respectively. Due to the data, there was a significant difference between the group in AF-Aloe with a dose of $100\left(14^{\text {th }}\right.$ day $)$ and 300 ( $28^{\text {th }}$ day $)$ ppm. Based on the finding, with increasing dose and day, the level of lipid oxidation decreased, which lead to oxidative yolk stability. 


\subsubsection{Egg production and egg weight.}

All birds were healthy during the trial period, and no mortality was detected among the groups. After a 4-week treatment, the treated groups' egg weight on days 14 and 28 was similar to the negative groups. Although no interruption and reduction in egg production were found in all treated groups, reduction of egg production was found in the group fed with $1575 \mu \mathrm{g}$ of AFB1/kg b.w (AF-0) on day 28, but it was not statically different. The finding is opposite to data reported by Herzallah (2013), that the hens received 894.12 ppb AFB1 in their diet decreased egg production [31]. Also, Zaghini et al., 2005 reported that diets with AFB1 levels of $2.5 \mathrm{ppm}$ in laying hens had no apparent effect on egg production [32].

\subsection{4. carotenoid in egg yolk.}

Yellowness in eggs is an acceptable factor for consumers. Carotenoids are responsible for yellow color in the egg, which is considered a class of lipid-soluble isoprenoid compounds $[33,34]$. This study showed no statistical difference among the groups. Previous studies showed a relation between egg production that leads to an increase in the level of carotenoid [34]. In the current work, no statistical reduction of egg production was detected. The mean level of carotenoid $0.017-0.018 \mu \mathrm{g} / \mathrm{kg}$ for negative groups, $0.018-0.019 \mu \mathrm{g} / \mathrm{kg}$ for positive groups, $0.017-0.019 \mu \mathrm{g} / \mathrm{kg}$ for AF-Aloe (100), and 0.017-0.018 $\mu \mathrm{g} / \mathrm{kg}$ for AF-Aloe(300) was found on day 14 and 28. The current finding is in agreement with results reported by Huff $e t$ al., 1975 [34], who evaluated the effects of dietary aflatoxin on egg yolk parameters.

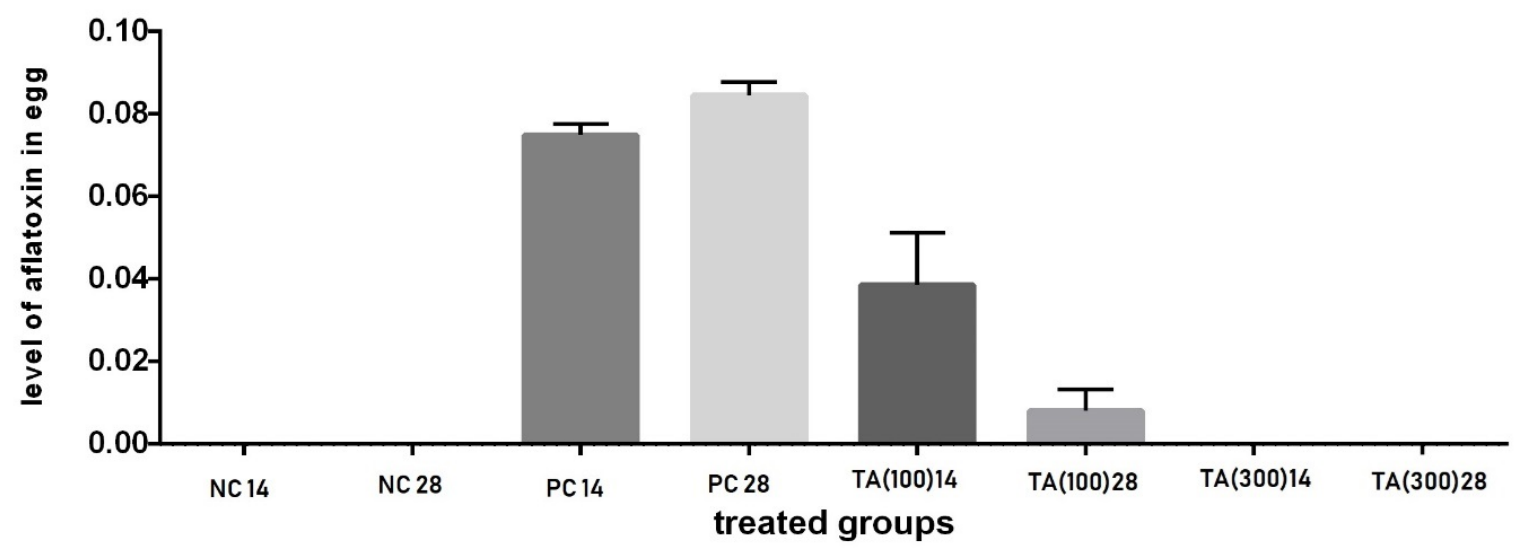

Figure 1. Concentration of AFB1 in treated groups.

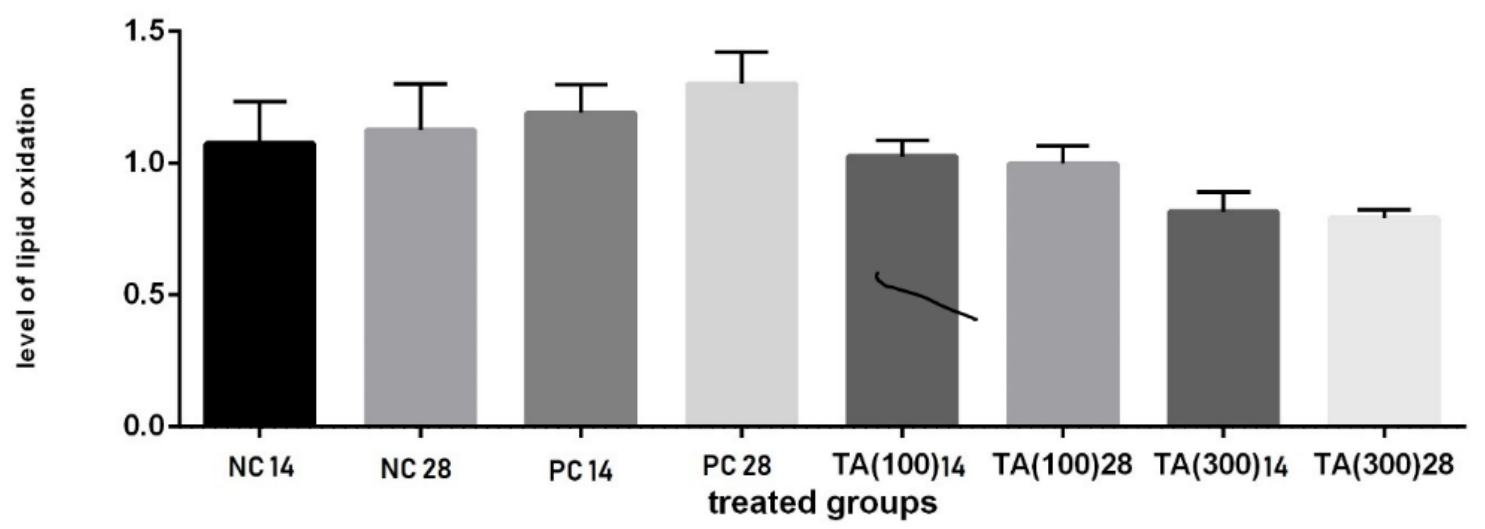

Figure 2. Level of lipid oxidation between groups. The inhibition of lipid oxidation by Aloe vera extract was observed in AF-Aloe with a dose of 300 ppm on day 28. 


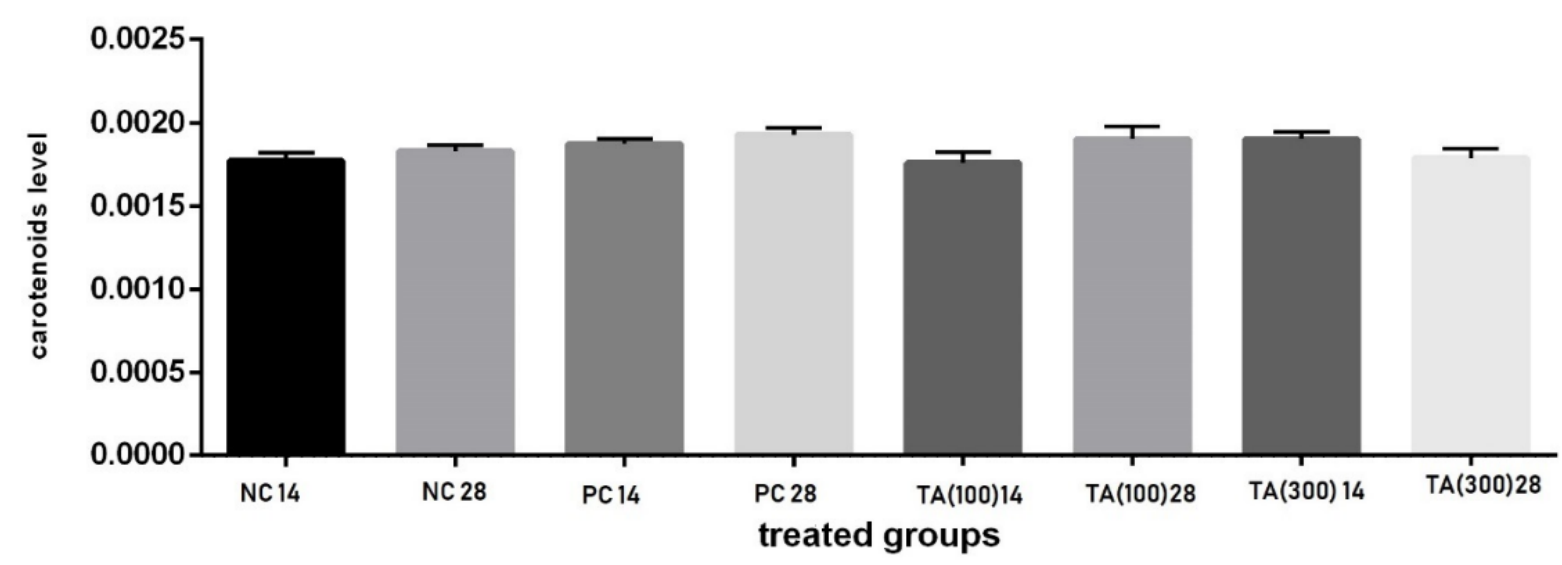

Figure 3. The level of carotenoids in treated groups.

Table 1. Effect of fed diets on laying hen.

\begin{tabular}{c|c|c}
\multicolumn{1}{c}{ Groups } & $\begin{array}{c}\text { Egg weight } \\
(\text { Mean } \pm \text { SD) }\end{array}$ & $\begin{array}{c}\text { Egg production } \\
(\%)\end{array}$ \\
\hline Negative control 14 & $63.5 \pm 4.49$ & 100 \\
\hline Negative control 28 & $61.01 \pm 3.78$ & 85 \\
\hline Positive control 14 & $62.25 \pm 3.40$ & 85 \\
\hline Positive control 28 & $62.09 \pm 3.46$ & 57 \\
\hline AF-Aloe (100) 14 & $61.06 \pm 3.92$ & 100 \\
\hline AF-Aloe (100) 28 & $60.77 \pm 3.55$ & 85 \\
\hline AF-Aloe (300) 14 & $61.57 \pm 2.54$ & 100
\end{tabular}

\section{Conclusions}

One of the important, most common, and worrisome contaminations around the world is Aflatoxins, especially Aflatoxin B1. This toxin is very strong and stable, which is hazardous to human and animal health. Since poultry feed is highly susceptible to Aflatoxin contamination; therefore, it can enter chicken feeds, meat, eggs and lead to toxicity in both humans and chickens. Accordingly, it is imperative to take effective and necessary measures to reduce this poison. Aloe vera extract plays an important role in reducing and inhibiting the toxicity of Aflatoxin B1. Therefore, it is recommended to be included in poultry feed as a food supplement.

\section{Funding}

The financial support of this study (Project No; 240/478) was provided by Tehran University of Medical Sciences, Tehran, Iran.

\section{Acknowledgments}

The authors want to thank the authorities of the Tehran University of Medical Science. This study's financial support (Project No; 240/478) was provided by the Tehran University of Medical Sciences, Tehran, Iran.

\section{Conflicts of Interest}

The authors declare no conflict of interest. 


\section{References}

1. Yuming, D.; Xinyue, L.; Kaifang, D.; Qisheng, P. Research Progress on Brucellosis. Curr. Med. Chem. 2019, 26, 5598-5608, http://dx.doi.org/10.2174/0929867325666180510125009.

2. Leslie, J.; Poschmaier, B.; Egmond, H.v.; Malachová, A.; de Nijs, M.; Bagi, F.; Zhou, J.; Jin, Z.; Wang, S.; Suman, M. The MyToolbox EU-China Partnership_Progress and Future Directions in Mycotoxin Research and Management. Toxins (Basel) 2020, 12, 712, https://doi.org/10.3390/toxins 12110712.

3. Sun, L.; Li, Y.; Wang, H.; Zhao, Q. An aptamer assay for aflatoxin B1 detection using Mg2+ mediated free zone capillary electrophoresis coupled with laser induced fluorescence. Talanta 2019, 204, 182-188, https://doi.org/10.1016/j.talanta.2019.05.069.

4. Adegbeye, M.J.; Reddy, P.R.K.; Chilaka, C.A.; Balogun, O.B.; Elghandour, M.M.M.Y.; Rivas-Caceres, R.R.; Salem, A.Z.M. Mycotoxin toxicity and residue in animal products: Prevalence, consumer exposure and reduction strategies - A review. Toxicon 2020, 177, 96-108, https://doi.org/10.1016/j.toxicon.2020.01.007.

5. Omotayo, O.P.; Omotayo, A.O.; Mwanza, M.; Babalola, O.O. Prevalence of mycotoxins and their consequences on human health. Toxicological Research 2019, 35, 1-7, https://doi.org/10.5487/TR.2019.35.1.001.

6. Wang, P.; Ma, L.; Jin, J.; Zheng, M.; Pan, L.; Zhao, Y.; Sun, X.; Liu, Y.; Xing, F. The anti-aflatoxigenic mechanism of cinnamaldehyde in Aspergillus flavus. Sci. Rep. 2019, 9, 10499, https://doi.org/10.1038/s41598-019-47003-z.

7. IARC (International Agency for Research on Cancer). Monographs on the evaluation of carcinogenic risks of human. Lyon, , France, 1993, IARC Press.

8. Qi, N.; Yu, H.; Yang, C.; Gong, X.; Liu, Y.; Zhu, Y. Aflatoxin B1 in peanut oil from Western Guangdong, China, during 2016-2017. Food Additives \& Contaminants: Part B 2019, 12, 45-51, https://doi.org/10.1080/19393210.2018.1544173.

9. Pleadin, J.; Frece, J.; Markov, K. Mycotoxins in food and feed. In Adv. Food Nutr. Res., Elsevier: 2019; 89, 297-345, https://doi.org/10.1016/bs.afnr.2019.02.007.

10. Dazuk, V.; Boiago, M.M.; Rolim, G.; Paravisi, A.; Copetti, P.M.; Bissacotti, B.F.; Morsch, V.M.; Vedovatto, M.; Gazoni, F.L.; Matte, F.; Gloria, E.M.; Da Silva, A.S. Laying hens fed mycotoxin-contaminated feed produced by Fusarium fungi (T-2 toxin and fumonisin B1) and Saccharomyces cerevisiae lysate: Impacts on poultry health, productive efficiency, and egg quality. Microb. Pathog. 2020, 149, 104517, https://doi.org/10.1016/j.micpath.2020.104517.

11. Mahato, D.K.; Lee, K.E.; Kamle, M.; Devi, S.; Dewangan, K.N.; Kumar, P.; Kang, S.G. Aflatoxins in Food and Feed: An Overview on Prevalence, Detection and Control Strategies. Front. Microbiol. 2019, 10, 2266, https://doi.org/10.3389/fmicb.2019.02266.

12. Krishnamurthy, Y.L.; Shashikala, J. Inhibition of aflatoxin B1 production of Aspergillus flavus, isolated from soybean seeds by certain natural plant products. Lett. Appl. Microbiol. 2006, 43, 469-474, https://doi.org/10.1111/j.1472-765X.2006.02011.x.

13. Nabila, V.K.; Putra, I.B. The effect of Aloe vera ethanol extract on the growth inhibition of Candida albicans. Med Glas (Zenica) 2020, 17, 485-489, https://doi.org/10.17392/1098-20.

14. Surjushe, A.; Vasani, R.; Saple, D.G. Aloe vera: a short review. Indian J. Dermatol. 2008, 53, 163, https://doi.org/10.4103/0019-5154.44785.

15. Cui, Y.; Cheng, Y.; Guo, Y.; Xie, Y.; Yao, W.; Zhang, W.; Qian, H. Evaluating the hepatoprotective efficacy of Aloe vera polysaccharides against subchronic exposure of aflatoxins B1. Journal of the Taiwan Institute of Chemical Engineers 2017, 76, 10-17, https://doi.org/10.1016/j.jtice.2017.03.040.

16. Jones, C. Development of an assay for Aflatoxin B1 in a range of foodstuffs using the Biacore Q surface plasmon resonance biosensor. PhD diss., Dublin City University, 2011.

17. Mohajer, A.; Araghi, A.; Sadighara, P. Oxidative stress and toxicity effect of Echium amoenum on mice brain. Comp. Clin. Path. 2019, 28, 397-401, https://doi.org/10.1007/s00580-019-02913-2.

18. Sicińska, P.; Bukowska, B.; Michałowicz, J.; Duda, W. Damage of cell membrane and antioxidative system in human erythrocytes incubated with microcystin-LR in vitro. Toxicon 2006, 47, 387-397, https://doi.org/10.1016/j.toxicon.2005.12.006.

19. AOAC final action method 17.002, colour of eggs. J. Assoc. Off. Anal. Chem. 1973, 56, 272.

20. Fakhri, Y.; Rahmani, J.; Oliveira, C.A.F.; Franco, L.T.; Corassin, C.H.; Saba, S.; Rafique, J.; Mousavi Khaneghah, A. Aflatoxin M1 in human breast milk: A global systematic review, meta-analysis, and risk 
assessment study (Monte Carlo simulation). Trends Food Sci. Technol. 2019, 88, 333-342, https://doi.org/10.1016/j.tifs.2019.03.013.

21. Ferreira, R.G.; Cardoso, M.V.; de Souza Furtado, K.M.; Espíndola, K.M.M.; Amorim, R.P.; Monteiro, M.C. Epigenetic alterations caused by aflatoxin b1: a public health risk in the induction of hepatocellular carcinoma. Translational Research 2019, 204, 51-71, https://doi.org/10.1016/j.trs1.2018.09.001.

22. Fouad, A.M.; Ruan, D.; El-Senousey, H.K.; Chen, W.; Jiang, S.; Zheng, C. Harmful effects and control strategies of aflatoxin b1 produced by Aspergillus flavus and Aspergillus parasiticus strains on poultry. Toxins (Basel) 2019, 11, 176, https://doi.org/10.3390/toxins11030176.

23. Markov, K.; Pleadin, J.; Bevardi, M.; Vahčić, N.; Sokolić-Mihalak, D.; Frece, J. Natural occurrence of aflatoxin B1, ochratoxin A and citrinin in Croatian fermented meat products. Food Control 2013, 34, 312317, https://doi.org/10.1016/j.foodcont.2013.05.002.

24. Iqbal, S.Z.; Nisar, S.; Asi, M.R.; Jinap, S. Natural incidence of aflatoxins, ochratoxin A and zearalenone in chicken meat and eggs. Food Control 2014, 43, 98-103, https://doi.org/10.1016/j.foodcont.2014.02.046.

25. Al-Ruwaili, M.; Alkhalaileh, N.I.; Herzallah, S.M.; Rawashdeh, A.; Fataftah, A.; Holley, R. Reduction of aflatoxin b1 residues in meat and organs of broiler chickens by lactic acid bacteria. Pak. Vet. J. 2018, 38, 325-328, https://doi.org/10.29261/pakvetj/2018.064.

26. Section 683.100 Action Levels for Aflatoxins in Animal Feeds (CPG 7126.33) [internet]. FDA, 2009. Available from http://www.abvt.org/public/docs/Aflatoxin_In_Animal_Feed.pdf.

27. Sumantri, I.; Herliani, H.; Yuliani, M.; Nuryono, N. Effects of zeolite in aflatoxin B1 contaminated diet on aflatoxin residues and liver histopathology of laying duck. IOP Conference Series: Earth and Environmental Science 2018, 207, 012017, https://doi.org/10.1088/1755-1315/207/1/012017.

28. Chung, T.K.; Ekdman, J.W.; Baker, D.H. Hydrated Sodium Calcium Aluminosilicate: Effects on Zinc, Manganese, Vitamin A, and Riboflavin Utilization. Poult. Sci. 1990, 69, 1364-1370, https://doi.org/10.3382/ps.0691364.

29. Edrington, T.S.; Kubena, L.F.; Harvey, R.B.; Rottinghaus, G.E. Influence of a superactivated charcoal on the toxic effects of aflatoxin or T-2 toxin in growing broilers. Poult. Sci. 1997, 76, 1205-1211, https://doi.org/10.1093/ps/76.9.1205.

30. Teniola, O.D.; Addo, P.A.; Brost, I.M.; Färber, P.; Jany, K.D.; Alberts, J.F.; van Zyl, W.H.; Steyn, P.S.; Holzapfel, W.H. Degradation of aflatoxin B1 by cell-free extracts of Rhodococcus erythropolis and Mycobacterium fluoranthenivorans sp. nov. DSM44556T. Int. J. Food Microbiol. 2005, 105, 111-117, https://doi.org/10.1016/j.ijfoodmicro.2005.05.004.

31. Saqer Mohammad, H. Aflatoxin B1 Residues in Eggs and Flesh of Laying Hens Fed Aflatoxin B1 Contaminated Diet. American Journal of Agricultural and Biological Sciences 2013, 8, https://doi.org/10.3844/ajabssp.2013.156.161.

32. Zaghini, A.; Martelli, G.; Roncada, P.; Simioli, M.; Rizzi, L. Mannanoligosaccharides and aflatoxin B1 in feed for laying hens: effects on egg quality, aflatoxins B1 and M1 residues in eggs, and aflatoxin B1 levels in liver. Poult. Sci. 2005, 84, 825-832, https://doi.org/10.1093/ps/84.6.825.

33. Hinton, C.F.; Fry, J.L.; Harms, R.H. Influence of a Xanthophyll-Free Pullet Grower Diet on Subsequent Egg Yolk Pigmentation1. Poult. Sci. 1974, 53, 223-226, https://doi.org/10.3382/ps.0530223.

34. Aamir Qureshi, M.; Javed, S. Structural dynamics studies on the binding of aflatoxin B1 to chicken egg albumin using spectroscopic techniques and molecular docking. J. Biomol. Struct. Dyn. 2020, 38, 3144-3155, https://doi.org/10.1080/07391102.2019.1652690. 